\title{
From left bundle branch block to Icelandic whales: the multiple perils of atrial fibrillation management in the elderly
}

\author{
Stefano Fumagalli ${ }^{1} \cdot$ Serena Boni $^{1} \cdot$ Debbie Gabbai $^{1} \cdot$ Ilaria Giannini $^{1}$ \\ Francesca Tarantini ${ }^{1} \cdot$ Niccolò Marchionni $^{1}$
}

Received: 23 July 2015/Accepted: 7 August 2015

(c) Springer International Publishing Switzerland 2015

\begin{abstract}
We present the case of an elderly woman which demonstrates how AF therapy in aged individuals is particularly challenging for the presence of complex conditions. The rhythm- or the rate control strategy must be carefully chosen based on individual risk profile. Oral anticoagulant therapy must be wisely managed to maximize benefits-in terms of stroke and dementia controland to reduce complications.
\end{abstract}

Keywords Anti-arrhythmic therapy - Atrial fibrillation . Elderly $\cdot$ New oral anticoagulants $\cdot$ Oral anticoagulants

\section{Introduction}

Atrial fibrillation (AF) is the most frequent sustained arrhythmia observed in elderly people [1]. Moreover, mortality and some clinically relevant complications of $\mathrm{AF}$, such as stroke, heart failure and dementia, are particularly common among aged individuals [1]. The clinical picture of elderly arrhythmic patients is often worsened by comorbidities and by a response to drug therapy which could be different from that observed at younger ages.

Stefano Fumagalli

fumadue@tin.it

1 Intensive Care Unit and Geriatric Arrhythmology Unit, Division of Geriatric Cardiology and Medicine, and Research Unit of Medicine of Aging, Department of Experimental and Clinical Medicine, University of Florence and AOU Careggi, Viale Pieraccini 6, 50139 Florence, Italy

\section{Case report}

We present the case of an 83-year-old woman. She was completely independent in basic and instrumental activities of daily living (IADL) and her mini mental state examination (MMSE) was quite normal. She was unmarried and lived alone. Before retirement, she worked as an herbalist and from this activity derived great skepticism in doctors and drug therapy. She does not drink coffee or alcoholic beverages and stopped smoking about 40 years ago. Only arterial hypertension was referred among cardiovascular risk factors. Clinical history resulted positive also for lung tuberculosis at young age, presence of uterine fibroids, which brought to radical hysterectomy at 35 years, cholecystectomy for gallbladder stones at 61 years, inguinal and crural hernias which were surgically repaired, bilateral cataract surgery and diagnosis of Sjogren syndrome. Her first episode of AF had been diagnosed 15 years before. All events, with a mean heart rate of about $140 \mathrm{bpm}$, were characterized by palpitations, had a variable length and were often triggered by meals. The echocardiogram was normal. ECG Holter had previously revealed an intermittent, heart-rate dependent, left bundle branch block and a CT coronary angiography showed a low probability of disease.

Despite a high-risk $\mathrm{CHA}_{2} \mathrm{DS}_{2}$-VASc score, which was equal to 4 (arterial hypertension, age $\geq 75$ years, female gender), she had always refused, for personal reasons, to start continuous therapy with oral anticoagulants and antiarrhythmic agents. Regardless the frequent advice of her doctor, she had decided to control AF episodes with a "pillin-the-pocket" strategy (propafenone, $300 \mathrm{mg}$ p.o.) [2]. In only one occasion, 4 years before, the patient was treated with external cardioversion. In the last 12 months, arrhythmic episodes became more frequent, with a cadence 
of about once a week. The old lady arrived in the emergency department at 2.00 PM on September 10th, 2014. She had contacted the Emergency Medical Service because of marked fatigue. Immediately after the arrival of the ambulance, she developed mental confusion, arterial hypotension and bradycardia. At the admission, cold diaphoresis, nausea and vomiting appeared. Repeated ECG demonstrated sinus bradycardia followed by sinus rhythm, with important electrical alterations characterized by 1 st degree AV conduction block (PR length: $250 \mathrm{~ms}$ ) and persistent QRS enlargement (QRS length: $240 \mathrm{~ms}$ with marked disturbance of left bundle branch conduction) (Fig. 1a). Once the patient was able to collaborate, it appeared that after having felt palpitations, she erroneously took an overdose of propafenone $(600 \mathrm{mg}$ - two tablets, and not the usual dose of $300 \mathrm{mg}$ - one tablet) because of the excitement for the arrival of her family. The old lady was then transferred to a monitored bed, where symptoms and ECG alterations disappeared. After $12 \mathrm{~h}$ from her arrival in hospital, arterial pressure was $165 / 75 \mathrm{mmHg}$ and HR 73 bpm. Body weight was $60 \mathrm{~kg}$, height $162 \mathrm{~cm}$ (BMI: $22.9 \mathrm{~kg} / \mathrm{m}^{2}$ ). Blood tests revealed mild anemia (Hb: $11.4 \mathrm{~g} /$ $\mathrm{dL}$, mean corpuscular volume: $82.6 \mathrm{fL}$ ), normal blood urea nitrogen and creatinine concentrations $(0.33 \mathrm{~g} / \mathrm{L}$ and $0.89 \mathrm{mg} / \mathrm{dL}$, respectively), transaminases and TSH values in the normal range. Troponin I did not show any change of clinical significance during the hospitalization. Interestingly, pro-BNP values decreased from $1033 \mathrm{pg} / \mathrm{mL}$, at baseline, to $288 \mathrm{pg} / \mathrm{mL}$, at $72 \mathrm{~h}$. Our patient remained in hospital 4 days. During her stay, she experienced two further episodes of AF, which required administration of i.v. amiodarone. No persistent alterations of conduction
Fig. 1 ECGs of the patient. Panel a after her arrival at the Emergency Department. It is possible to see the $\mathrm{P}$ waves (red circles) and the deep alterations of AV (PR length: $250 \mathrm{~ms}$ ) and intraventricular (QRS length: $240 \mathrm{~ms}$; blue circles) conduction. Panel b Atrial fibrillation relapse recorded while the patient was in hospital; the intraventricular conduction is normal after propafenone washout (blue circles)
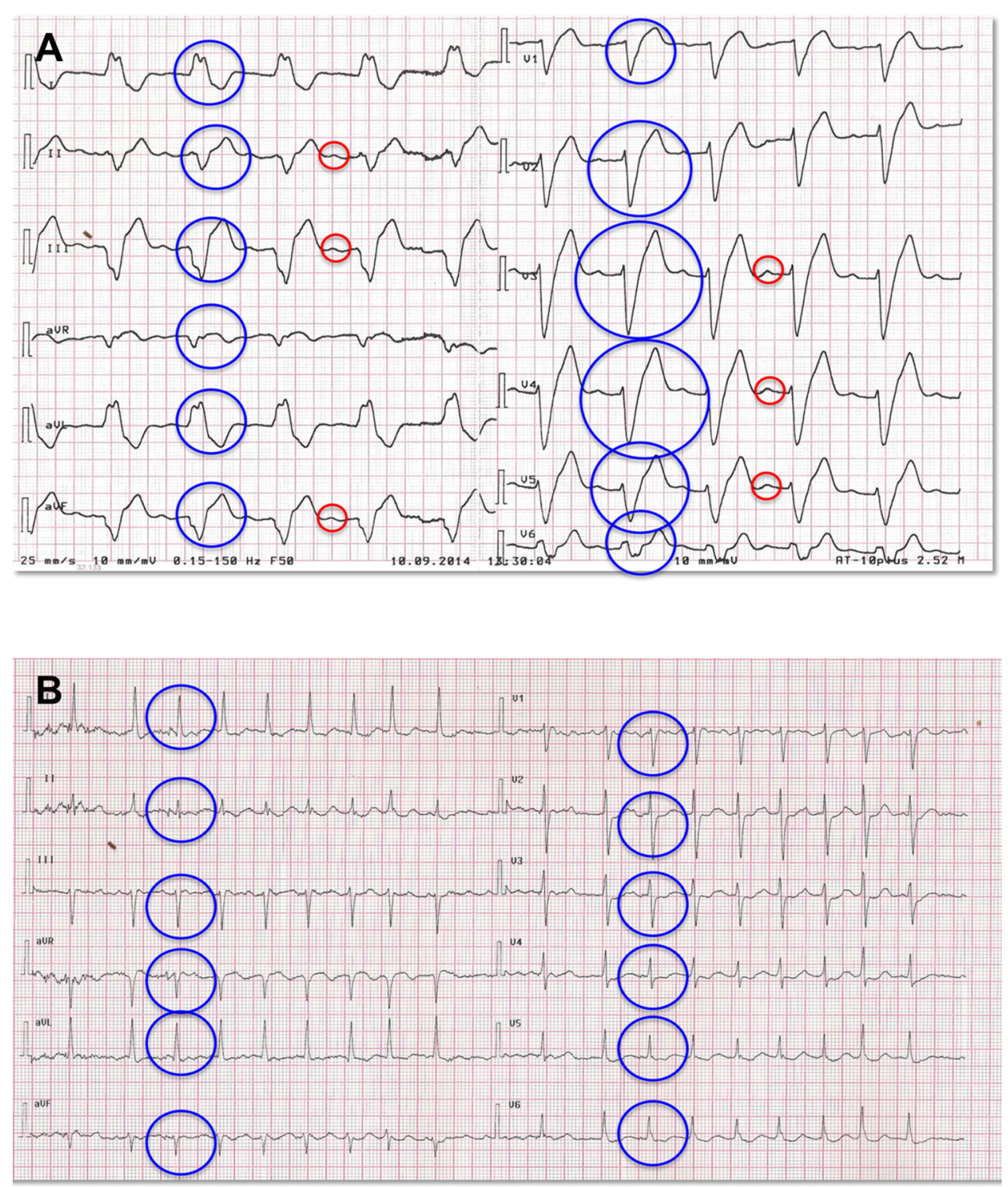


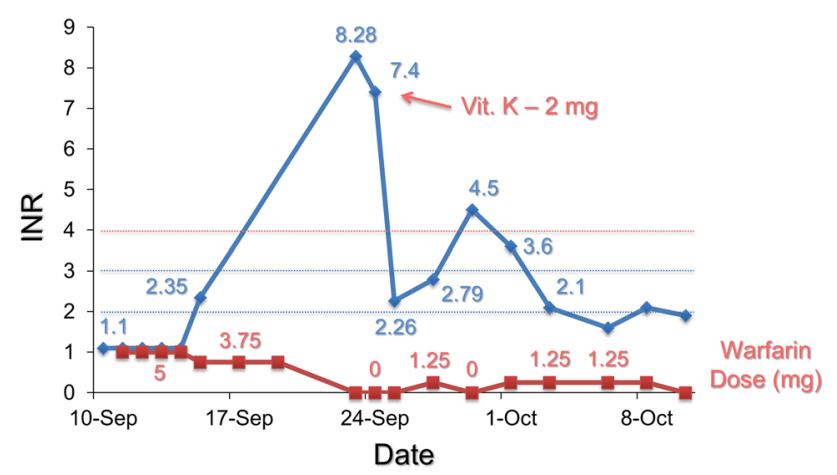

Fig. 2 Daily trends of INR values (blue solid line) and of warfarin dose (red solid line). The blue dotted lines represent the INR range for patients with non valvular atrial fibrillation; the red dotted line identifies the INR value from which the hemorrhagic risk increases. The arrow is in correspondence of vitamin $\mathrm{K}$ administration

were observed at ECG (Fig. 1b). The drug effectively stopped the arrhythmia and the old lady was discharged with amiodarone and warfarin on September 14th. Because of a misinterpretation of hospital prescription, warfarin was maintained at a daily dose of $3.75 \mathrm{mg}$ for 4 days. This determined a marked increase of INR values, which forced to the administration of Vitamin K (2 mg p.o.) (Fig. 2). INR dropped immediately in the normal therapeutic range. However, in the following days, despite a relevant reduction of warfarin daily dose (between 0 and $1.25 \mathrm{mg}$ ), it was possible to observe a marked instability of INR values, which ranged from 1.6 to 4.5 (Fig. 2). HAS-BLED score was 4 (arterial hypertension, INR instability, age $>65$ years, use of non-steroidal anti-inflammatory agents). On this basis, we started treatment with a new oral anticoagulant. Since then, in the subsequent 9 months, our old patient maintained a stable clinical condition. No AF relapses were recorded; no adverse effects related to oral anticoagulation were experienced. The patient is in touch with our center to which she constantly sends clinical information. She is still independent, living a socially active life and fostering her interests. At this regard, she has recently sent us an e-mail about the need to save Icelandic whales.

\section{Discussion}

This case clearly shows the multiple problems correlated to AF management in elderly individuals. Moreover, the selection of the most appropriate plan is sometimes made difficult for the existence of conflicting evidence in literature. A rhythm control strategy is more rarely chosen in aged patients and, indeed, the AFFIRM Study showed an increased mortality with this approach in subjects older or equal to 70 years [3]. Furthermore, the "pill-in-the-pocket" therapy should not be employed over 75 years of age [2] and strong evidence proves the high adverse event rate associated with all anti-arrhythmic agents [1]. However, the same AFFIRM Study demonstrated that, independently of the adopted therapeutic strategy, the presence of sinus rhythm was significantly associated with a reduced mortality during the follow-up [4]. Specifically regarding elderly people, AF development independently accelerated the decline of cognitive performance [5]. An item of the IADL, explicitly explores the possibility of an elderly patient to take a medication in a correct dosage at a correct time. Our patient, completely independent in her usual tasks, failed to assume the right dose of propafenone because of an emotional stress (i.e., the visit of her relatives). It is reported that anxiety symptoms can significantly decrease memory performance and negatively influence executive functioning capabilities of older adults [6]. Thus, even temporary mood disturbances can exert important effects on the possibility to properly follow a therapeutic scheme in elderly individuals.

Concerning oral anticoagulation, undertreatment of aged subjects currently represents an important issue [7]. In our old lady, we observed an initial marked increase of INR values determined by a misinterpretation of warfarin prescription. At this regard, to limit the hemorrhagic complications of an oral anticoagulant regimen in the elderly, it has been shown that it is necessary to have a careful management plan conducted by experienced centers [8]. In our patient, we observed an important instability of INR and a related low time in therapeutic range (TTR), even after having begun a more solicitous monitoring protocol. Advanced age, female gender and the use of amiodarone itself could be at least in part responsible of this unsatisfactory result [9]. Importantly, it has been recently demonstrated the complex relation between anticoagulation and dementia in older AF patients. In fact, the lower the MMSE, the lower is the TTR [10]; furthermore, in elderly subjects without dementia or cerebrovascular diseases at baseline, evidence shows that lower TTR is associated with a higher long-term risk of dementia [11]. The choice of a new oral anticoagulant with a specific action on the coagulation cascade, a more defined pharmacologic profile, a lower interaction with drugs or meals, fewer monitoring requirements and a significantly reduced risk of intracranial hemorrhage, revealed to be the most appropriate.

In conclusion, $\mathrm{AF}$ therapy in elderly individuals is particularly challenging for the presence of complex conditions. The rhythm- or the rate control strategy must be carefully chosen based on individual risk profile. Oral anticoagulant therapy must be wisely managed in order to maximize benefits-in terms of stroke and dementia control—and to reduce complications. 
Acknowledgments We thank Carlo Fumagalli for his assistance in manuscript preparation.

\section{Compliance with ethical standards}

Conflict of interest The authors have no conflict of interest to disclose regarding this case report.

Ethical approval All procedures performed in this case report are in accordance with the institutional ethical standards and with current guidelines recommendations.

Informed consent The patient gave her consent to the presentation of this clinical case.

\section{References}

1. January CT, Wann LS, Alpert JS, Calkins H, Cigarroa JE, Cleveland JC Jr et al (2014) 2014 AHA/ACC/HRS guideline for the management of patients with atrial fibrillation: a report of the American College of Cardiology/American Heart Association Task Force on Practice Guidelines and the Heart Rhythm Society. J Am Coll Cardiol 64:e1-e76

2. Alboni P, Botto GL, Baldi N, Luzi M, Russo V, Gianfranchi L et al (2004) Outpatient treatment of recent-onset atrial fibrillation with the "pill-in-the-pocket" approach. N Engl J Med 351:2384-2391

3. Shariff N, Desai RV, Patel K, Ahmed MI, Fonarow GC, Rich MW et al (2013) Rate-control versus rhythm-control strategies and outcomes in septuagenarians with atrial fibrillation. Am J Med 126:887-893

4. Corley SD, Epstein AE, DiMarco JP, Domanski MJ, Geller N, Greene HL et al (2004) Relationships between sinus rhythm, treatment, and survival in the atrial fibrillation follow-up investigation of rhythm management (AFFIRM) Study. Circulation 109:1509-1513

5. Thacker EL, McKnight B, Psaty BM, Longstreth WT Jr, Sitlani CM, Dublin S et al (2013) Atrial fibrillation and cognitive decline: a longitudinal cohort study. Neurology 81:119-125

6. Yochim BP, Mueller AE, Segal DL (2013) Late life anxiety is associated with decreased memory and executive functioning in community dwelling older adults. J Anxiety Disord 27:567-575

7. Fumagalli S, Said S, Laroche C, Gabbai D, Marchionni N, Boriani G et al (2015) Age-related differences in presentation, treatment, and outcome of patients with atrial fibrillation in Europe: the EURObservational research programme-atrial fibrillation (EORP-AF) general pilot registry. JACC Clin Electrophysiol. doi:10.1016/j.jacep.2015.02.019 (in press)

8. Poli D, Antonucci E, Testa S, Tosetto A, Ageno W, Palareti G (2011) Bleeding risk in very old patients on vitamin $\mathrm{K}$ antagonist treatment: results of a prospective collaborative study on elderly patients followed by Italian Centres for Anticoagulation. Circulation 124:824-829

9. Garcia D, Regan S, Crowther M, Hughes RA, Hylek EM (2005) Warfarin maintenance dosing patterns in clinical practice: implications for safer anticoagulation in the elderly population. Chest 127:2049-2056

10. Flaker GC, Pogue J, Yusuf S, Pfeffer MA, Goldhaber SZ, Granger CB et al (2010) Cognitive function and anticoagulation control in patients with atrial fibrillation. Circ Cardiovasc Qual Outcomes 3:277-283

11. Jacobs V, Woller SC, Stevens S, May HT, Bair TL, Anderson JL et al (2014) Time outside of therapeutic range in atrial fibrillation patients is associated with long-term risk of dementia. Heart Rhythm 11:2206-2213 